\title{
Homofobia na construção das masculinidades hegemônicas: queerizando as hierarquias entre gêneros
}

\section{Homophobia in the making of hegemonics masculinities: queering the hierarchies between genders}

\section{Homofobia en la construcción de las masculinidades hegemónicas: queerizando las jerarquías entre los géneros}

\section{Caio Andrêo*}

Universidade Estadual Paulista "Júlio de Mesquita Filho" - UNESP, Assis, São Paulo, Brasil

\section{Wiliam Siqueira Peres**}

Universidade Estadual Paulista "Júlio de Mesquita Filho" - UNESP, Assis, São Paulo, Brasil

\section{André Masao Peres Tokuda***}

Universidade Estadual Paulista "Júlio de Mesquita Filho" - UNESP, Assis, São Paulo, Brasil

\section{Leonardo Lemos de Souza****}

Universidade Estadual Paulista “Júlio de Mesquita Filho" - UNESP, Assis, São Paulo, Brasil

\begin{abstract}
RESUMO
A presente discussão tem por objetivo problematizar a homofobia enquanto uma das linhas que dão manutenção aos domínios da masculinidade hegemônica em relação às outras sexualidades e expressões de gêneros (masculinidades e feminilidades). O termo "homofobia" apareceu primeiramente nos Estados Unidos, em 1971, e pode ser atribuído ao ato de hostilidade para com o homossexual, além de uma manifestação arbitrária que coloca $x$ outrx como opostx, anormal ou inferior, evidenciando assim seu caráter sexista. A prática homofóbica é construída durante o processo de socialização de muitos homens, que ainda na infância têm como premissas básicas a imediata diferenciação com relação às mulheres e o ódio contra os homossexuais. Por isso, a pluralização de masculinidades que rompam com a lógica hierárquica binária e universalizante entre as sexualidades torna-se um importante dispositivo de combate à homofobia. Os estudos queer, nesse sentido, podem se tornar contribuição importante nesse combate, por meio da desconstrução dos regimes e normas que ainda restringem as discussões referentes às sexualidades, promovendo a ideia de "identidades múltiplas", abrindo assim alternativas para que as pessoas expressem as infinitas possibilidades de pluralização da vida humana.
\end{abstract}


Palavras-chave: masculinidades, homofobia, teoria queer.

\begin{abstract}
The present dicussion have as aim to problematize the homofobia as one of the lines that provide maintenance the domains of hegemonic masculinities in relative the others sexualities and genders expressions (masculinities and femininities). The term "homophobia" emerges first in the United States, in 1971, the term can be attributed as an act of hostility toward homosexual, besides being an arbitrary manifestation that puts the other as opposite, abnormal or inferior, thus demonstrating its sexist character. The homophobic practice is constructed during the process of socialization of many men, that still in infancy have as the basic premises the immediate differentiation with respect the women and hatred against homosexuals. Therefore, the pluralization of masculinities that break with the binary hierarchical logic and universalizing between sexualities becomes an important device to combat homophobia. The Queer studies, accordingly, may become an important contribution to this combat, through the deconstruction of regimes and standards that still restrict the discussions concerning sexuality, promoting the idea of "multiple identities", thereby opening alternatives so that people express the infinite possibilities of pluralization of human life.
\end{abstract}

Keywords: masculinities, homophobia, queer theory.

\title{
RESUMEN
}

La presente discusión tiene por meta discutir la homofobia mientras una de las líneas que mantiene los dominios de la masculinidad hegemónica en relacion las otras sexualidades y expresiones de géneros (masculinidades y feminidades). El término "homofobia" apareció por primera vez em los Estados Unidos, en 1971, y puede ser asignado el acto de hostilidad en la hacia homosexual, allá una expresión arbitraria que pone el otro como opuesto, anormal o inferior, demostrando así su carácter sexista. La práctica homofóbica se construye durante el proceso de socialización de muchos hombres, que todavía en la infancia tiene como premisa básico la diferenciación inmediata con relación las mujeres y el odio contra los homosexuales. Por lo tanto, la pluralización de masculinidades que se rompen con la lógica jerárquico binario y universalizante entre las sexualidades se convierte en un importante dispositivo para luchar contra la homofobia. Los estudios Queer, en consecuencia, puede convertirse en importante contribución en este lucha, a través de la deconstrucción de los regímenes y normas que aún restringe las discusiones relativa a las sexualidades, promoción de la idea de "múltiples identidades", abriendo así alternativas para que las personas expresar un sinfín de posibilidades de pluralización de la vida humana.

Palabras clave: masculinidades, homofobia, teoría queer.

\section{Sobre as hierarquias de gêneros: apresentando o contexto a ser problematizado}

Diversas reivindicações, críticas, debates e problematizações promovidos e conquistados por parte de movimentos sociais que tratam de questões de gêneros, raças/cores e sexualidades têm sido agenciados durante as últimas décadas no Brasil e no mundo, 
sobretudo advindas de grupos feministas, movimentos gays, lesbianos e, mais recentemente, através das políticas e teorias queer, as quais passaram a contemplar pessoas que não se sentiam inseridas e acolhidas por esses grupos e movimentos. Esse contexto promoveu a manifestação de inquietudes em relação às normatizações dadas até então, como por exemplo, o patriarcado, a heteronormatividade obrigatória e tantas outras formas de controle e poder que despotencializam e excluem certa parcela da população (mulheres, gays, lésbicas, travestis, transexuais, entre outras) (Boris, 2011; Garcia, 2005; Hickey-Moody \& Asmussen, 2009; Sáez, 2007; Welzer-Lang, 2001).

Assim, apesar de alguns avanços conquistados em meio a essas reivindicações e debates, as violências de gêneros ainda se fazem presentes, sejam em suas formas mais sutis através de piadas e/ou comentários de cunho depreciativo ou mesmo por meio daquelas que deixam marcas físicas, sempre contra aquelxs consideradxs passíveis, mulheres, gays, travestis, transexuais, entre outrxs. Entre essas violências temos a homofobia, que se pode dizer ser produto do sistema sexo-gênero que hierarquiza e normatiza tais relações em favor da masculinidade hegemônica (Boris, 2011; Connell, 2000; Connell \& Messerschmidt, 2013; Rubin, 1975; Sáez, 2007; WelzerLang, 2001).

Desse modo, a presente discussão tem por objetivo problematizar a homofobia enquanto uma das linhas que dão manutenção aos domínios da masculinidade hegemônica em relação às outras sexualidades e expressões de gêneros dissidentes. Da mesma forma, esse texto não se propõe a exaurir a respeito de uma discussão ainda bastante inicial na Psicologia a respeito das masculinidades e suas ações subjetivantes, mas, introduzir o tema como referência da produção de subjetividades masculinizantes que contribuem para a produção e manutenção da homofobia. Para mapear mais de perto a construção dessa manutenção, faz-se necessário apresentar alguns aspectos das relações hierárquicas que se concretizam enquanto discursos dos gêneros.

De início, precisaremos mapear os modos de produção e funcionamento da construção dos gêneros em nossa sociedade que passa pelo dispositivo da sexualidade. Para isso necessitamos delinear, com brevidade, como as sexualidades foram, ao longo do tempo, sendo produzidas e vinculadas à natureza e utilizadas como bases legitimadoras de uma ordem social que regula e gerencia a produção das diferenças e desigualdades, passando a servir quase como lei para justificar os discursos dos dominantes (classe média e alta, heterossexuais, brancos, machos), determinando que podiam estabelecer normas de dominação - como, por exemplo, dos homens sobre as mulheres, dos brancos sobre os negros, dos heterossexuais sobre os homossexuais, para estabelecer o dito e o não dito, quem 
pode ou não viver, se aceito ou não na sociedade (Córdoba, 2005; Foucault, 2006; Rubin, 2003).

$\mathrm{Na}$ contramão, teóricos como Michel Foucault concebiam as sexualidades como algo não natural e sim, como uma construção social. Em seu livro "História da sexualidade I - A vontade de saber" ao problematizar sobre a emergência do biopoder nos alerta a respeito dos dispositivos disciplinares que agem sobre os corpos de modo a adestra-los para serem úteis à produção capitalista e dóceis diante das ordens do poder. Nesses processos de regulação e disciplinarização dos corpos, as sexualidades surgem como um dos pontos mais vigiados e controlados das expressões humanas, sendo criado para isso o que Foucault chamou de dispositivo da sexualidade. Como modo de definição, Foucault (2007, p. 244) propõe a ideia de dispositivo como sendo:

[...] um conjunto decididamente heterogêneo que engloba discursos, instituições, organizações arquitetônicas, decisões regulamentares, leis, medidas administrativas, enunciados científicos, proposições filosóficas, morais, filantrópicas. Em suma, o dito e o não dito são os elementos do dispositivo. 0 dispositivo é a rede que se pode manter entre esses elementos.

Esse dispositivo consiste em tecnologias e estratégias utilizadas para conter e disciplinar os corpos. Desta forma, para Foucault (1988), a burguesia construiu ao longo dos séculos XVIII e XIX diversos dispositivos para dominar e disciplinar os corpos, inclusive da classe trabalhadora. Logo, a naturalização das sexualidades serviu e ainda serve como forma para que os trabalhadores e trabalhadoras monopolizem suas energias para o trabalho, tornando-se úteis para a lógica capitalista e dóceis diante das ações do poder (Córdoba, 2005; Penedo, 2008).

Partindo desses pressupostos, Gayle Rubin (2003) afirma que o sexo foi, ao longo dos tempos, sendo reprimido e construído como uma prática pecaminosa, ou seja, quando vai além do sexo reprodutivo e antes do casamento, principalmente pelas instituições religiosas cristãs, e mais tarde pela medicina, psiquiatria e psicologia, que patologizaram práticas sexuais que fogem do sexo para procriação ou "tradicionais".

Pensamos com isso que a desnaturalização das sexualidades e dos gêneros é importante para a produção das subjetividades e emancipação de individualidades que são dominadas. Essas problematizações se iniciaram com a crítica de Gayle Rubin (1975) ao sistema sexo/gênero, calcada na dicotomia entre natureza (sexo) e cultura (gênero), no entanto, a primeira noção só se complementa com a segunda. Assim os gêneros são as roupas que se colocam no cabide (sexo), ou seja, são aplicações de significados que cada 
sociedade impõe aos sexos biológicos. Com isto, o sistema sexo/gênero reflete a formação das mulheres (ou mais especificamente os estereótipos do que é ser mulher - delicada, educada, passiva, cuidadora do lar, entre outros atributos); e dos homens (viril, destemido, ativo, independente e provedor, entre outros predicados) (Butler, 2003; Córdoba, 2005; Penedo, 2008).

Rubin (1975) anuncia que o sistema sexo/gênero serve como um dispositivo para controlar e disciplinar as pessoas, logo, de organização social. Com isso, o mesmo funciona como uma tecnologia que auxilia a subordinação das mulheres aos homens, dos homossexuais aos heterossexuais, construindo uma sociedade machista e heteronormativa, que tem no patriarcado sua base de sustentação (Córdoba, 2005; Penedo, 2008; Peres; 2013; Salih, 2012).

Judith Butler (2003), algum tempo depois, acrescentou ao sistema sexo/gênero os desejos e práticas sexuais; com isso, segundo as políticas heteronormativas, os sujeitos deveriam se enquadrar nesse sistema, ou seja, uma pessoa que nasce com o sexo de macho, deverá ter o gênero masculino, desejo heterossexual e ser ativa na prática sexual, e quem nasce com o sexo de fêmea, deverá ter gênero feminino, desejo heterossexual e prática sexual passiva; criando-se assim um código de inteligibilidade, homogeneização e padronização das identidades sociais. Qualquer expressão que divirja dessas proposições será tratada como abjeção, ou seja, não será reconhecido como humano, sendo tratado como monstruosidade. (Hickey-Moody \& Asmussen, 2009; Peres, 2013).

Vale ressaltar, como coloca Susana Penedo (2008), que heterossexuais e homossexuais, e tantas outras pessoas que fogem das normas, sofrem com a política da heteronormatividade compulsória. Ou seja, todas estão reprimidas, disciplinadas e controladas por esses dispositivos/tecnologias. Assim, homens do gênero masculino, com práticas e desejos heterossexuais necessitam todos os dias de uma autoafirmação desses papéis, como muito bem colocou Judith Butler (2003), ao trazer à luz a teoria da performatividade em que discursos normativos de sexos e gêneros se inscrevem sobre os corpos. Para a autora, a identidade é construída no interior da linguagem, dos discursos e das instituições. Desta forma, desde que nascemos somos "generificadxs", colocam-nos uma máscara/fantasia e deste modo nos fazemos - através da repetição destes atos - homens ou mulheres heterossexuais. Com isso vão se criando políticas identitárias, que aprisionam e controlam as pessoas, submetendo-as a "papéis aprovados" pela sociedade.

Tais produções de subjetividades são controladas e estabelecidas através de regimes de verdades binárias e universais e acabam por aprisionar os corpos em meras identidades. Essas normas foram construídas e estabelecidas a priori do nascimento dos bebês, mas se 
atualizam frequentemente a partir da resposta dada à clássica pergunta: "é menino ou menina?". A partir dessa questão, diversas regras são impostas de acordo com o sexo do bebê. Se for do sexo macho, seu gênero será exclusivamente masculino, futuramente terá relações sexuais com mulheres e com penetração. No caso de criança com o sexo de fêmea, seu gênero será feminino e terá relações sexuais com homens, e também envolvendo penetração, mas de forma passiva (Pichardo, 2012; Salih, 2012; Welzer-Lang, 2001).

Essas acepções a respeito dos modelos dados de como praticar sexo e sentir ou não prazer restrito ao ideal heteroprocriativo e restrito a papéis sexuais e de gêneros, se conecta a diversas instâncias outras de base regulatória sobre os corpos e seus sistemas de funcionamentos, tais como, sensoriais, perceptivos, cognitivos e afetivos bastante comprometidos pelas ações do binarismo e do sedentarismo que reduzem nossos corpos, sexos, gêneros, desejos a um eu, um indivíduo, a uma identidade.

Esse modo de organização social e de vida promoveu a naturalização da sexualidade, a invisibilidade e a inviabilidade de outras formas de sexualidades, desejos e práticas sexuais, dando assim legitimação para as desigualdades entre sexos e os gêneros, denunciando seu caráter sexista. Essa legitimação falocêntrica de desigualdades naturaliza modos de violências que podem ser constatadas pelos relatórios de pesquisas nacionais e internacionais que denunciam os crescentes números a cada ano de feminicídios, assassinatos de LGBTs e pessoas negras, se comparadas com as brancas, e de pessoas que fogem às normas, seja por seu desejo e/ou pela sua prática sexual ${ }^{1}$.

Nesse sentido, a visão dicotômica e binária masculino/feminino, heterossexual/homossexual permaneceu por muito tempo nas discussões referentes às sexualidades, promovendo determinados modos de vida condizentes com certos padrões de masculinidades e feminilidades mantidos dentro dessas normas, criando identidades fixas. De modo que quem se atrevia a atravessar essas fronteiras era concebido como antinatural, doentio, pecador, ultrajante e inominável (Pichardo, 2012).

Assim, após essa breve cartografia da construção das sexualidades e dos gêneros, iremos destacar as construções das masculinidades. Com isso, pensamos que a construção do masculino se dá de forma subjetiva, ou seja, se desenvolve de maneira individual e particularizada. Cabe ressaltar que existem aspectos comuns aos homens de uma mesma cultura, classe econômica e raça, contudo o que se questiona aqui é a ideia de "identidade masculina" como algo fechado, cristalizado e universal.

Essa identidade masculina é duramente criticada por propiciar a dominação do homem, principalmente sobre as mulheres, e outras dissidências da heteronormatividade, assim como por promover mais 
do que a manutenção das desigualdades entre os gêneros, também a hegemonia de certo padrão de masculinidade, heterossexual, branca, cristã, de classe alta, racional e impenetrável. Com isso, a masculinidade hegemônica, conceito apresentado por Robert 2 Connell (2000), predominou e ainda predomina em muitos contextos atuais, presentes dentro do campo do exercício das masculinidades, sendo remetido à heterossexualidade obrigatória, racionalidade e privilégio de poder e a uma série de condutas e referências que deviam ser seguidas pelos "homens de verdade". Podemos demarcar aqui processos de subjetivação normatizadoras que produzem pessoas restritas a essa lógica dominante, na qual a "casa dos homens", apresentada por Daniel Welzer-Lang (2001), que diz respeito a um conjunto de rituais que fazem do menino um aprendiz de como ser homem/macho através da experiência da dor vivida nos esportes, na submissão aos adultos e relações de socialização; vem de encontro a essas subjetivações que aliadas a sistemas regulatórios subjetivam corpos, desejos e práticas que se submetem ao falocentrismo e à misoginia.

Toda a discussão envolvendo esses conceitos surgiu das teorias feministas numa ordem patriarcal de gêneros, que promoveram discussões sobre os papéis dos homens dentro dessa configuração, já na década de 1970. Nesse mesmo período ocorreram diversas críticas à normatização dos papéis masculinos como modos dos comportamentos de muitos homens (Connell, 2013).

$\mathrm{Na}$ tentativa de conceituação, deparamo-nos com a concepção de masculinidade cuja constituição se baseia em diversos atributos e atitudes que são esperados dos homens em diferentes contextos culturais, ou seja, através de traços normatizadores e cristalizadores que vão definir práticas sociais do que é ser "homem" (Connell, 2013; Welzer-Lang, 2001).

Essas desigualdades são dadas como modelares desde a infância e produzem crenças de que os homens são superiores e diferentes das mulheres e daqueles outros homens que divergem dos modelos previamente dados. Isto é evidenciado através de biopolíticas regulatórias presentes no sistema sexo/gênero/desejo/práticas sexuais, produzindo sexismos, machismos, misoginias e homofobias (Boris, 2011; Butler, 2003).

A educação de crianças do sexo de macho produz no masculino a ideia de que, para ser homem, deve-se combater os aspectos que poderiam associá-los às mulheres (misoginia/machismo/sexismo/homofobia, sensibilidades), além de aprenderem a estar com os homens, aceitar a lei dos maiores e mais velhos e os ritos que se traduzem em operadores hierárquicos, conforme podemos constatar nas discussões apresentadas por Welzer-Lang (2001). Isto se assemelha com a fala de Boris (2011), para quem as diferenças encontradas entre grupos de meninos e de 
meninas se constroem nas formas de socialização da criança segundo seu sexo a partir do nascimento, o que varia muito por causa dos diferentes cuidadorxs, mas explica a diversidade das experiências humanas.

Logo, é possível dizer que existe em grande parte de nossa sociedade um modelo fechado de masculinidade, que define os lugares, discursos e expressões que "os homens" devem assumir, para que as normas dadas pelo biopoder e os processos de captura e regulação biopolítica sejam mantidos, bem como para que se mantenha a estrutura das relações de gêneros "esperadas" (Foucault, 1988, 2008). Essa visão de mundo se constrói por meio da dinâmica familiar, social e das relações que são estabelecidas, abarcando crenças de superioridade do gênero masculino, na qual valores atrelados à autoridade e à moral familiar, como a disciplina, valentia, coragem e a identificação com a hierarquia, são incorporados às vivências dos modos de ser homem.

As determinações desses modos de ser homem são produzidas através da ordem do discurso que Foucault (1999) nos adverte, e sua eficácia se atualiza pelo uso da disciplina, do discurso disciplinar, considerando que:

A disciplina é um princípio de controle da produção do discurso. Ela lhe fixa os limites para o jogo de uma identidade que tem a forma para a reatualização permanente das regras. Tem-se o hábito de ver na fecundidade de um autor, na multiplicidade dos comentários, no desenvolvimento de uma disciplina, como que recursos infinitos para a criação dos discursos. Pode ser, mas não deixam de ser, princípios de coerção, e é provável que não se possa explicar seu papel positivo e multiplicador, se não se levar em consideração sua função restritiva e coercitiva. (Foucault, 1999, p.10)

Desta forma, assim como coloca Simone de Beauvoir (1980), acreditamos que a mulher não nasce mulher, mas se "constrói" como mulher, o mesmo deve-se aplicar ao homem, com isso o mesmo não nasce homem, ele torna-se homem. Ou seja, o ser humano não é predeterminado, ou determinado somente biologicamente, mas construído socialmente através de negociações políticas, assim como, de seus desejos, suas subjetividades e diferenças.

Com isso, pode-se entender que as características entre masculinos e femininos estão sempre em mudança, em construção permanente mediante a sua inserção em um dado contexto social, histórico e cultural. Desta forma, a masculinidade não seria unicamente determinada por aspectos biológicos, mas também pelos aspectos psíquicos e sociais, não sendo apenas vinculada a uma única 
possibilidade de ser "homem", possibilitando-nos pensar em "múltiplas masculinidades" (Boris, 2011; Connell, 1995).

Portanto, ao invés de pensarmos em uma masculinidade hegemônica com contornos bem definidos, limitados e fechados em si, como ainda é pensada, entendemos que há cruzamentos de múltiplos componentes de subjetivação que se ligam, desligam e religam, influenciando a construção da subjetividade das pessoas, se opondo ao modelo binário, assim, nos permitindo falar de diversos gêneros e masculinidades (Deleuze \& Guattari, 1995).

Quando não se foge do binarismo, ocorre a dominação masculina tanto no espaço privado como no público, culminando em violências sobre as mulheres, dissidências sexuais e de gêneros decorrentes dos privilégios sociais, culturais, materiais e subjetivos restritos às pessoas do sexo de machos e ativos. Desta forma, quem não se enquadra na ideia de masculino, produzida pelas regulações da biopolítica e do biopoder, passam a ser associados à figura feminina, passiva e dominada (Hickey-Moody \& Asmussen, 2009; Welzer-Lang, 2001).

A partir da década de 1980 começa a se rejeitar a ideia de uma única masculinidade e dedica-se a defender a diversidade humana. Ao se pensar nas masculinidades, tomamos estas enquanto construções sociais, políticas e históricas, rejeitando a ideia de uma masculinidade única e abrindo espaço para a manifestação da pluralidade humana, pois não há um modelo de masculinidade que esteja presente a todas as épocas e culturas (Boris, 2011; Welzer-Lang, 2001).

Nas últimas décadas têm surgido movimentos e grupos sociais e teóricxs insatisfeitxs com os efeitos normativos sobre seus corpos, que começam a problematizar essas capturas. Assim, em torno de todas essas discussões teóricas e políticas, temos o surgimento das políticas e teorias Queer ${ }^{3}$. Em meados dos anos 90, teóricxs lesbianxs, que se comprometiam com as lutas contra a homofobia e os movimentos feministas, deram início a reflexões teóricas sobre os movimentos sociais Queer, que já lutavam contra as políticas identitárias; entre elxs estavam Teresa de Lauretis, Judith Butler, Eve Kosofsky Sedgwick e muitxs outrxs (Córdoba, 2005; Miskolci, Simões, 2007; Sáez, 2007; Salih, 2012).

Assim, os Estudos Queer surgem problematizando e fazendo críticas às políticas identitárias, pois, negam o caráter natural da identidade (antiessencialista), fixo e estabelecido, ou seja, trazendo a ideia de que as identidades são múltiplas e socialmente construídas. Dessa forma, não se perde/exclui outras linhas/experiências (Penedo, 2008; Salih, 2012). Deste modo, entende-se a identidade/subjetivação como construção social que está sempre aberta e em constante transformação. Assim, a política identitária é fortemente criticada dentro dos Estudos Queer por seu caráter regulador, excludente e opressivo em relação às minorias, como mulheres, lésbicas, gays, 
transexuais, travestis, pobres, negrxs, asiáticxs, entre muitas outras (Penedo, 2008).

Percebe-se deste modo, que as masculinidades são negociadas e construídas, então podem também ser desconstruídas, ou seja, não é necessário que se cristalizem a partir de uma identidade masculina definitiva e acabada, como ocorre no processo de subjetivação das masculinidades desde a infância, é necessária a desconstrução dos enquadres do que é ser do gênero masculino ou feminino.

\section{Os processos de subjetivação das masculinidades se iniciam na infância}

A respeito do processo de construção dessas masculinidades, Daniel Welzer-Lang (2001) traz contribuições muito significativas, ao indicar que diversas práticas homofóbicas começam a ser aprendidas para que o menino se torne um "homem de verdade". Nesse grupo, pelo qual ele denominou "casa dos homens", as relações se pautam no esquema iniciado-iniciador, no qual os homens mais velhos corrigem os mais novos de modo que busquem o acesso à virilidade, caracterizando o que esse autor denominou de "viriarcado".

Esse acesso é iniciado por práticas de homossociabilidades que ocorrem quando as crianças do sexo masculino deixam o mundo das mulheres para se reagruparem com outros meninos de sua idade. Nesse grupo, aprendem que o sofrimento é necessário para que se tornem homens, o que consiste em aceitar a lei dos mais velhos e a distinção das mulheres, que são colocadas como o seu extremo oposto. A partir desse momento, os operadores hierárquicos falocentricos começam a se manifestar e se compor com estéticas masculinizantes reducionistas produtoras dos homens.

Através do sofrimento psíquico, social e corporal são promovidas violências, num primeiro momento contra eles mesmos, e depois contra os outros meninos. Essa tendência é orientada pela lógica da masculinidade que se afirma enquanto oposta e superior a outras manifestações de gêneros. O masculino então se torna submisso a esse modelo que promove a obtenção de privilégios. Para isso, muitos abusos são cometidos, não apenas de ordem sexual, mas também de ordem física e psicológica através de golpes, ofensas, ameaças, gozações e controles, de forma a atribuir formas de rivalidade ao feminino. De modo que aquele que se associa a uma mulher sofre repulsa da parcela masculina à que está ligado social e culturalmente.

Mesmo adultos muitos homens frequentam a "casa dos homens" (Welzer-Lang, 2001), a partir de lugares nos quais a sua masculinidade será reafirmada, em oposição aos não homens. Dessa forma, a manutenção da homofobia vai se concretizando ao longo da 
formação dessas masculinidades que se consideram fechadas e intransponíveis. Ainda a esse respeito, Welzer-Lang, (2001), acrescenta:

A homofobia é uma forma de controle social que se exerce entre os homens, isso desde os primeiros passos da educação masculina. Para ser valorizado, o homem precisa ser viril, mostrar-se superior, forte, competitivo...senão é tratado como os fracos e como as mulheres, e assimilado aos homossexuais. Homofobia e dominação das mulheres são as duas faces de uma mesma moeda. Homofobia e viriarcado constroem entre as mulheres e entre os homens as relações hierarquizadas de gênero. A homofobia é o produto, no grupo dos homens, do paradigma naturalista da superioridade masculina que deve se exprimir na virilidade (p.118).

A construção desse modo específico de ser homem reflete sofrimentos iniciais dos meninos desde os primeiros passos, para que não sejam associados às mulheres e aos homossexuais, de modo a assegurar a hegemonia sobre eles, através da reprodução de discursos e práticas machistas, heterossexistas e homofóbicas produzidas contra esses mesmos grupos.

\section{A homofobia no interior das masculinidades}

O termo "homofobia", de acordo com Daniel Borrillo (2009) apareceu pela primeira vez nos Estados Unidos, em 1971, sendo que apenas no final da década de 90 ele começou a fazer parte dos dicionários europeus. A ele pode ser atribuído o ato de hostilidade para com os homossexuais, mas não apenas isso. A homofobia aparece enquanto uma manifestação arbitrária que coloca o outro como oposto, anormal ou inferior, evidenciando assim seu caráter sexista e excludente. Em outras designações, o outro pode ser até considerado "não humano", relegando a prática homossexual à condição de crime abominável, amor pecaminoso ou mesmo uma tendência perversa ou uma prática infame, marginal e excêntrica.

De modo complementar, Welzer-Lang apresenta a homofobia como sendo "a discriminação para com as pessoas que mostram, ou a quem se emprestam certas qualidades (ou defeitos) atribuídos ao outro gênero" (2001, p.118). Borrillo (2009) aponta que houve uma mudança epistemológica e política quanto à maneira pela qual a homofobia era abordada. Epistemologicamente, ela passou da simples percepção quanto a sua origem e funcionamento para a análise dessa hostilidade provocada por um modo de orientação 
sexual. No âmbito político, a questão passou de homossexual para homofóbica.

Nesse sentido, a homofobia passou a se caracterizar como uma forma de inferiorização, consequência direta da hierarquia entre as sexualidades e os gêneros, na qual a heterossexualidade foi elevada a um status superior, natural e normal. Nos próprios dicionários, segundo Borrillo (2009), essa questão aparece bem clara. A homossexualidade é tratada como sinônimo de inversão, pederastia e lesbianismo, todos os termos relacionados opostamente à heterossexualidade. Além disso, a desproporção linguística aparece em expressões como "sapatão", "bichinha", "afeminado" ou em forma de insultos conforme aponta Javier Saèz (2011), como em "que te den por el culo" (que podemos traduzir como "vai tomar no cu"). Segundo o mesmo autor, tais expressões criam realidades comprometidas pelo falocentrismo e pelo machismo e transmitem valores reducionistas que podem demarcar uma identidade para quem os recebe, sendo dessa maneira assinalado.

Com isso, criam-se fronteiras que colocam a heterossexualidade em detrimento da homossexualidade, bem como, do gênero masculino em relação ao feminino. O comportamento heterossexual, dessa forma, funciona como modelo social que não reproduz a questão biológica das espécies necessariamente, mas sim, a reprodução de uma ordem social. Vale ressaltar que a prática homofóbica não está restrita apenas a homossexuais, mas àqueles e aquelas que não aderem à ordem clássica dos sexos e dos gêneros, tais como travestis, transexuais, bissexuais, transgêneros, intersexos e mesmo mulheres e homens heterossexuais que não respondem aos comportamentos esperados para cada gênero (Pichardo, 2012). Com o advento das lutas sociais emancipatórias por questões específicas voltadas para as demandas de travestis e transexuais, podemos hoje falar em transfobia, assim como, das questões específicas de necessidades lésbicas de falarmos em lesbofobia, por exemplo, o respeito à identidade de gênero e de direitos à hormonização e cirurgia de transgenitalização, voltados para as travestis e homens e mulheres trans, enquanto questões ginecológicas de mulheres lésbicas, ou ainda, do estupro corretivo que busca tornar lésbicas, heterossexuais, colocam em evidência o surgimento da lesbofobia (Pichardo, 2012).

E por que a homossexualidade é tão temida por muitas pessoas? Ora, ela se torna insuportável a partir do momento que os homossexuais reivindicam atravessar a fronteira que separa e hierarquiza os heterossexuais. Mais do que isso, ela representa, num primeiro momento, sentimentos de medo, aversão, nojo e repulsa.

Essa reivindicação coloca em questão a posição de poder ocupada por muitos homens heterossexuais, sendo que a grande maioria dos que ocupam essa situação de poder e privilégios não se pergunta do 
porquê de gozar de mais direitos, acessos e de privilégios por suas posições hegemônicas, nem sequer das origens destas, propiciando manifestações da homofobia em seus mais variados modos, em espaços públicos e privados.

Borrillo (2009) traz uma classificação da homofobia, dividindo-a em homofobia afetiva (psicológica) e cognitiva (social). Na primeira, por conter uma manifestação de caráter emotivo, a homossexualidade é condenada. Já na segunda, ela é tolerada nos espaços íntimos e privados, desde que não goze dos mesmos direitos concedidos aos heterossexuais. Dessa maneira, o autor aponta que a prática homofóbica não é apenas aquela em que há um insulto ou agressão direta aos homossexuais e a todxs aquelxs que não correspondem à ordem clássica de definição dos gêneros, mas também ocorre em práticas sutis de combate e intolerância, através de piadas, representações caricaturais e expressões de cunho depreciativo presentes na linguagem cotidiana.

Com isso, a homofobia geral é a pura manifestação do sexismo. Nela há uma espécie de "vigilância de gênero", pois qualquer deslize cometido do masculino em relação ao feminino e vice-versa é lembrado para que assim se retorne ao "gênero adequado". Quando esse deslize é efetivado, a pessoa se torna traidora e desertora do gênero ao qual pertencia "naturalmente", por isso deve ser punida com palavras de cunho depreciativo ("viado", "sapatão", entre outros termos).

A homofobia específica reflete a intolerância direta a gays e lésbicas. No caso especial das lésbicas, Borrillo (2009) lembra que estas sofrem um duplo preconceito, pois além de serem mulheres, são homossexuais. Desse modo, o autor complementa "como qualquer outra manifestação de intolerância, a homofobia se constrói em torno de emoções (crenças, preconceitos, convicções, fantasmas...), de condutas (atos, práticas, procedimentos, leis...) e de um dispositivo ideológico (teorias, mitos, doutrinas, argumentos de autoridade...)" (Borrillo, 2009, p.28).

Além dessas duas formas de concretização (cognitiva e afetiva), a homofobia pode ser expressa também de forma comportamental (comportamentos), liberal (no âmbito privado), externalizada (condutas e emoções) e internalizada ou interiorizada (incorporação de mensagens, sentimentos e atitudes) (Pichardo, 2012).

Segundo essa noção, Borrillo (2009) afirma que a homofobia é um elemento constitutivo da identidade masculina, e se configura como um problema que também atravessa muitos homens heterossexuais, pois impede o estabelecimento de relações mais próximas entre eles, bem como a manifestação mútua de sentimentos e afetos. O autor complementa afirmando que essa situação tem origem durante 0 processo de socialização masculina através de competições, medo da fraqueza, controle dos sentimentos e a própria homofobia que vão 
modelar um jeito específico e hegemônico de ser homem: rude, grosseiro, desordeiro, agressivo, violento e competitivo.

Dessa forma, o medo em ser associado às mulheres e homossexuais e o ódio promovido contra esses mesmos grupos se torna um elemento poderoso na construção da masculinidade hegemônica, pois a produção de virilidade se torna um aspecto que afasta o temor da homossexualidade para muitos. A esse respeito, Sáez e Carrascoza (2011) complementam:

Es interesante señalar que esta dinámica del miedo nos muestra que «ser un hombre» es un lugar vacío. Es decir, es imposible escribir o definir en qué consiste ser hombre. $\mathrm{Ni}$ siquiera eso que llamamos masculinidad es algo privativo 0 propio de los hombres, como ha mostrado Judith Halberstam en su trabajo pionero sobre la participación de las mujeres en la creación de la masculinidad (Masculinidad femenina). Vemos en estos procesos que «ser un hombre» se basa en «no ser» otras cosas: no ser mujer, no ser homosexual. Es una identidad generada por oposición, por negación, o por la repetición de unos gestos estéticos o de conducta que carecen de original, es una noción sin un contenido preciso. El poder de los hombres, el poder patriarcal y machista, se construye, por una parte, por medio de ese desprecio hacia las mujeres $y$, por otra parte, por el odio hacia los hombres considerados como menos masculinos, los gays (p.62) ${ }^{4}$.

De modo suplementar, os autores afirmam que esses discursos machistas e homofóbicos, gerados por uma série de oposições, negações e repetições se tornam regimes de discursos e práticas imperativas que se reafirmam em expressões cotidianas, criando uma realidade que legitima e dá manutenção ao patriarcado, garantindo a posição dominante da masculinidade hegemônica.

Com isso, o fortalecimento dessas práticas e discursos em muitos homens passa por esse olhar superior sobre as mulheres e o ódio contra os homossexuais, que no fundo pode ser um medo secreto do desejo homossexual, da parte homossexual que atravessa sua subjetividade, a qual deseja apagar. Javier Sáez e Sezo Carrascoza (2011) afirmam que há um pânico moral em ser homossexual e uma repressão do desejo homossexual que permeia nossa cultura. Essa negação ou pânico moral faz com que sejam promovidos diversos insultos homofóbicos, criando assim expressões a partir das quais habitualmente criam realidades e transmitem valores.

$O$ insulto, para quem o recebe, pode demarcar uma identidade, sendo inscrito e assinalado como inferior. A homofobia mostra-se enquanto um mecanismo de defesa, uma manifestação cultural e social muito comparável ao racismo e ao antissemitismo (discriminação contra os 
judeus). Ela pode promover o ódio de muitos homossexuais contra si próprios por conta dos estereótipos e estigmas sociais a que são submetidos, tais como os citados, e de diversos sentimentos que atravessam essa condição, provocando sofrimentos que podem levar a depressões, transtornos alimentares, dificuldades de socialização, problemas de aprendizagem, chegando, em muitos casos ao suicídio, conforme aponta Pichardo (2012). Pesquisas como as realizadas por Fernando Silva Teixeira Filho e Carina Rondini (2012), têm confirmado os resultados de pesquisas internacionais de que entre 10 alunxs LGBT (lésbicas, gays, bissexuais, travestis, homens e mulheres trans) em situação escolar, um terço ou 30\% já teve ideação suicida ou tentaram o suicídio.

Sáez (2011) afirma que a masculinidade em muitos homens se constrói na condição de se diferenciarem de alguns estereótipos projetados nas mulheres e homossexuais, como exemplo, enquanto estes penetrarem mulheres e mesmo outros homens, não devem se considerar homossexuais, pois xs "bichas" é que são penetradxs. Nesse sentido, segundo aponta o autor, ser homem é "ser ativo" e "impenetrável", sendo que ser ativo ou passivo está ligado historicamente através das relações dominador-dominado dentro da perspectiva do binário. $O$ autor complementa afirmando que a masculinidade, a virilidade e o heterossexual se sustentam na impenetrabilidade, e quando o homem deixa de ser impenetrável ocorre um "deslizamento de sexo e de gênero" a partir do qual passa a ser associado à mulher e sua orientação sexual passa de heterossexual para homossexual. Desse modo, o homem que se faz macho, quando penetra é restaurado como macho, masculino, homem viril para que assim sua "naturalidade" seja expressa, e, portanto, a universalidade de seu poder e privilégios seja executada e garantida.

\section{Considerações finais}

Através das discussões que envolvem a construção das masculinidades hegemônicas e suas práticas no processo de socialização de muitos homens, passando pela hierarquização entre os gêneros e contribuindo diretamente para a prática da homofobia, problematizaremos agora alguns elementos.

Vale lembrar que a homofobia, segundo aponta Borrillo (2009), é constituída a partir da intolerância, desrespeito, emoções e dispositivos ideológicos e não atingem apenas homossexuais, mas também aqueles que atravessam as fronteiras normativas entre as sexualidades e os gêneros. Ela pode ser manifestada desde sua forma mais sutil, através de comentários e/ou piadas de cunho depreciativo ou mesmo por agressões verbais e físicas, muitas das vezes 
culminando em destituição de direitos, perseguição e morte. Mais do que um ato violento, a homofobia demonstra uma manifestação arbitrária contra aqueles que são considerados anormais, avessos e até "não-humanos", transformando discursivamente a homossexualidade em uma prática perversa e demoníaca. A ideia de abjeção discutida por Judith Butler (2003) contribui para esclarecer o quanto as pessoas não heterossexuais são colocadas à margem da sociedade, tendo seu direito fundamental à singularidade e ao exercício pleno da cidadania participativa impedido, nas tomadas de decisões e de promoção de políticas públicas concretas e viáveis que de fato sejam garantidas a todas e todos.

Quando falamos em abjeção nos reportamos aquelas pessoas que não são reconhecidas enquanto sujeitos de direitos, ou seja, por não terem esse reconhecimento se inserem nas categorias do não humano, das monstruosidades, gerando uma ambiência de hostilidades e exclusões que promovem como espaços de existências as marginalidades. A abjeção se mostra como uma via de mão dupla considerando que ao mesmo tempo em que nega a humanidade a essas pessoas se coloca como referencia que atesta a normalidade como padrão absoluto do exercício de ser, estar e circular no mundo. Nesta perspectiva podemos considerar o quando as ações do sistema sexo/gênero/desejo/práticas sexuais em consonância com o dispositivo da sexualidade produzem a homofobia em detrimento das masculinidades hegemônicas discutidas por (Connell, 2000; Borrillo, 2009; Butler, 2003; Welzer-Lang, 2001; 2004) que se aliam na feitura de sujeitxs úteis para a produção capitalista e dóceis para a submissão às ordens do poder falocêntrico que tanto privilegia os viciados em identidades e desejosos das normas heteronormativas, 0 quer por sua vez corre riscos de fomentar subjetivações que autorizam as práticas homofóbicas e suas violências correlatas.

Ao se pensar que a prática homofóbica é construída durante o processo de socialização de muitos homens, ainda na infância, conforme apontam Welzer-Lang (2001) e Boris (2011), uma das premissas básicas para a construção do "homem" é a imediata diferenciação com relação às mulheres e o ódio contra os homossexuais, levando muitos meninos a passarem por sofrimentos psicossociais e corporais, sendo orientados a serem agressivos, viris e competitivos, para manter certo distanciamento da mútua troca de sentimentos e aproximações entre eles, modelando assim um jeito hegemônico de ser homem e respeitado por seus pares.

De modo geral, problematizamos que a categoria homofobia, devido a sua origem etimológica, estar associada à perspectiva médica, muitas das vezes, é limitada a esse contexto, quando politicamente, devido não termos ainda a criminalização da homofobia no Brasil, perdemos a oportunidade de ampliar o debate e o enfrentamento das 
violências, exclusões e assassinatos vividos pelos homossexuais, que deveriam ser associados à ideia de crimes de ódio.

Desse modo, podemos apontar que a manutenção da masculinidade hegemônica pode propiciar a prática da homofobia, com status de crime hediondo, se considerarmos os modos pelos quais se efetivam os processos de subjetivação das masculinidades aprisionadas pela heterossexualidade compulsória e o falocentrismo propriamente dito. Por isso, a pluralização de masculinidades capazes de romper com a lógica hierárquica binária e universalizante entre as sexualidades torna-se um importante dispositivo de combate à homofobia, pois, como nos aponta Suzana Lopes Penedo (2008), alertando-nos inclusive para a emergência de posições que ela vem denominando de hetero-queer, aquele que apesar de ser heterossexual se mostra solidário às lutas por direitos das mulheres e homossexuais e têm práticas sexuais mais abertas com suas parceiras, praticando a bissexualidade e/ou sadomasoquistas, expressando sensibilidades não esperadas para os homens de verdades, auxiliam na educação dos filhos e afazeres domésticos.

De modo complementar, Sáez e Carrascoza (2011), como modo de problematização das emergências da homofobia, do machismo e discriminações em geral, temos que passar pela relação do anal, da prática anal com o erotismo, dos sexos, gêneros, masculinidades, feminilidades e relações sociais. Esses processos de subjetivação normatizadores devem ser iniciados principalmente em instituições familiares e educacionais, passando também pela constante formação dos profissionais que nelas atuam e que, muitas vezes, ainda dão manutenção a essas normas e convenções com relação às sexualidades, raças/cores e classes sociais.

O medo e o ódio, o nojo e a ignorância devem dar lugar à informação e à desconstrução de discursos e práticas que ainda enrijecem as formas de homofobia, devem ampliar os conceitos e regimes de verdades restritos ao modelo procriativo heterosexista de modo a positivar a diversidade de práticas eróticas sexuais possíveis na obtenção de prazeres, gozos e novos posicionamentos diante da vida como valor maior. Vale lembrar que essas práticas não devem ser restritas apenas aos homens, apesar destes serem os seus principais autores, mas deve servir também àqueles e àquelas que estão reféns do paradigma naturalista de divisão entre os sexos e gêneros e que não aceitam as pessoas que possam romper com as fronteiras do sistema sexo/gênero/desejo/práticas sexuais (Butler, 2003). Podemos ainda apostar que as práticas homofobias são produzidas nas relações entre as pessoas e instituições, de modo que, são sempre negociações de poder e de manutenção aos modelos hegemônicos dos modos de ser homem e mulher nas sociedades ocidentais contemporâneas. 
Os estudos queer, nesse sentido, podem se mostra como uma contribuição importante de combate à homofobia, transfobia, lesbofobia, machismo, misoginia e sexismo, por meio da desconstrução dos regimes de verdades e normas falocêntricas que ainda restringem as discussões referentes às sexualidades, promovendo à ideia de "identidades múltiplas" (Penedo, 2008), que atestam de uma vez por todas que o ser humano não se limita a ideia de individuo, restritos a crença de um único corpo, único sexo, único gênero, mas se expressa em suas diversas formas da diversidade humana.

Muito mais do que "aceitar" as diferenças em suas variações - e isso não deve ser feito apenas criando leis para inibir e combater a cultura homofóbica - devemos nos atentar aos processos de subjetivação de muitos meninos e meninas que tem suas identidades sexuais e de gêneros inicialmente construídas por discursos e práticas regulatórias e disciplinadoras de seus corpos já no espaço familiar e que se seguem nos outros contextos de socialização, de modo a romper com essas configurações de discursos e práticas que ainda legitimam o patriarcado e o falocentrismo como modelo único de subjetivação, para assim abrir possibilidades para que as pessoas expressem as infinitas alternativas de pluralização da vida humana. Nesta perspectiva, novos possíveis são anunciados para que no mínimo consigamos construir uma sociedade um pouco mais acolhedora, emancipatória, menos homofóbica, transfóbica, lesbofóbica, racista, machista e sexista, em que nenhuma expressão dos corpos, dos sexos, dos gêneros, das sexualidades, das raças/cores se tornem polícia das outras.

\section{Referências}

Beauvoir, S. O. (1980). Segundo Sexo: A Experiência Vivida. Trad. Sérgio Milliet. Vol. 2, Rio de Janeiro, Brasil: Nova Fronteira.

Borrillo, D. (2009). A homofobia. In: Diniz, D., \& Lionço, T. (Orgs.) Homofobia e educação: um desafio ao silêncio (pp. 15-46). Brasília, Brasil: Editora UnB.

Boris, G. D. J. B. (2011). Falas de homens: a construção da subjetividade masculina. São Paulo, Brasil: Annablume.

Butler, J. (2003). Problemas de gênero: feminismo e subversão da identidade. Rio de Janeiro, Brasil: Civilização Brasileira.

César, M. R. A., Duarte, A., \& Sierra, J. C. (2013, maio/agosto). Governamentalização do Estado, movimentos LGBT e escola: capturas e resistências. Educação, 36(2), 192-200.

Connell, R. W. (1995). Políticas da Masculinidade. Educação \& Realidade, 20(2), pp. 185-206. 
Connell, R. W. (2000, september). Understanding men: Gender sociology and the new international research on masculinities. University of Sidney. Recuperado em 10 de outubro, 2014, de http://www.europrofem.org/contri/2_04_en/research-onmasculinities.pdf

Connell, R. W. , \& Messerschmidt, W. J. (2013, janeiro/abril). Masculinidade hegemônica: repensando o conceito (F. B. M. Fernandes, Trad.). Revista Estudo Feministas, 21(1), 241-282.

Córdoba, D. (2005). Teoría Queer: reflexiones sobre sexo, sexualidad e identidad. Hacia una politización de la sexualidad. In: Córdoba, D., Saéz, J., \& Vidarte, P. (Orgs.). Teoría Queer: políticas bolleras, maricas, trans, mestizas. (pp. 21-66). Barcelona, Espanha: Editorial Egales.

Deleuze, G., \& Guattari, F. (1995). Mil platôs: capitalismo e esquizofrenia, vol. 1. Rio de J aneiro, Brasil: Editora 34.

Foucault, M. (1988). História da sexualidade I: a vontade de saber. Rio de Janeiro, Brasil: Graal.

Foucault, M. (1999). A verdade e as formas jurídicas. Rio de Janeiro, Brasil: Nau Editora.

Foucault, M. (2006). Estratégia, poder-saber. Rio de Janeiro, Brasil: Forense Universitária.

Foucault, M. (2007). Sobre a história da sexualidade. In: M. Foucault. Microfísica do poder (pp. 243-276). Rio de Janeiro: Graal.

Foucault, M. (2008). Segurança, território, população: curso dado no Collège de France (1977-1978). São Paulo, Brasil: Martins Fontes.

Garcia, D. C. (2005). Teoria queer: reflexiones sobre sexo, sexualidad e identidad hacia uma politización de la sexualidade. In: Córdoba, D., Saéz, J., \& Vidarte, P. (Orgs). Teoria Queer. Políticas Bolleras, maricas, trans, mestizas (pp. 21-66). Barcelona y Madrid, Espanha: Editorial Egales.

Garcia, L. P., Freitas, L. R. S. de, Silva, G. D. M. da, \& Höfelmann, D. A. et. al. (2015). Estimativas corrigidas de feminicídios no Brasil, 2009 a 2011. Revista Panamericana de Salud Publica, 37(4/5), 251-257.

Hickey-Moody, A., \& Rasmussen, M. L. (2009). The sexed subject inbetween Deleuze and Butler. In: Nigianni, C., \& Storr, M. (Orgs.). Deleuze and Queer theory (pp. 37-53). Edinburgh, Estados Unidos: University Press.

Miskolci, R. , \& Simões, J. A. (2007). Dossiê Sexualidades Disparatadas (apresentação). Cadernos Pagu, 28, 9-18.

Penedo, S. L. (2008). El Laberinto Queer: Ia Identidad en tiempos del neoliberalismo. Barcelona, Espanha: Egales.

Peres, W. S. (2013). Psicologia e Políticas Queer. In: Filho, F. S. T., Peres, W. S., Rondini, C. A., \& Souza, L. L. de (Orgs). 
Queering: problematizações e insurgências na psicologia contemporânea (pp.55-63). Cuiabá, Brasil: Ed. UFMT.

Pichardo, J. I. (2012). El estigma hacia personas lesbianas, gays, bisexuales y transexuales. In: Gaviria, E., García-Ael, C., \& Molero, F. (Coords.). Investigación-acción. Aportaciones de la investigación a la reducción del estigma (pp. 111-125). Madrid, Espanha: Sanz y Torres.

Rubin, G. (1975). The Traffic in Women: Notes on the 'Political Economy' of Sex. In: Reiter, R. (ed.). Toward an Anthropology of Women (pp. 27-62). New York, Estados Unidos da América: Monthly Review Press.

Rubin, G. (2003). Pensando sobre sexo: notas para uma teoria radical da política da sexualidade. Campinas, Brasil: Mimeo.

Sáez, J. , \& Carrascosa, S. (2011). Por el culo. Políticas anales. Madrid/ Barcelona, Espanha: Editorial Egales.

Sáez, J. (2007). El contexto sociopolítico de surgimento de la teoría queer. In: Córdoba, D., Saéz, J., \& Vidarte, P. (Orgs). Teoría queer: políticas bolleras, maricas, trans, mestizas (pp. 67-76). Madrid, Espanha: Ed. Egales.

Salih, S. (2012). Judith Butler e a teoria Queer. Belo Horizonte, Brasil: Autêntica Editora.

Teixeira-Filho, F. S., \& Rondini, C. A. (2012, outubro). Ideações e tentativas de suicídio em adolescentes com práticas sexuais hetero e homoeróticas. Saúde e Sociedade, 21(3), 651-667.

Welzer-Lang, D. (2001). A construção do masculino: dominação das mulheres e homofobia. Revista Estudos Feministas, 9(2), 460482.

Welzer-Lang, D. (2004). Os homens e o masculino numa perspectiva de relações sociais de sexo (M. P. Grossi, Trad.). In: Schpun, M. (Org.) Masculinidades (pp.107-128). São Paulo/Santa Cruz do Sul, Brasil: Boitempo/Unisc.

\section{Endereço para correspondência \\ Caio Andrêo}

Universidade Estadual Paulista "Júlio de Mesquita Filho" (UNESP)

Faculdade de Ciências e Letras de Assis

Av. Dom Antonio, 2100, Parque Universitário, CEP 19806-900, Assis - SP, Brasil

Endereço eletrônico: caioandreo@gmail.com

Wiliam Siqueira Peres

Universidade Estadual Paulista "J úlio de Mesquita Filho" (UNESP)

Faculdade de Ciências e Letras de Assis

Av. Dom Antonio, 2100, Parque Universitário, CEP 19806-900, Assis - SP, Brasil

Endereço eletrônico: pereswiliam@gmail.com

André Masao Peres Tokuda

Universidade Estadual Paulista "Júlio de Mesquita Filho" (UNESP)

Faculdade de Ciências e Letras de Assis

Av. Dom Antonio, 2100, Parque Universitário, CEP 19806-900, Assis - SP, Brasil

Endereço eletrônico: andremasao@hotmail.com 


\section{Leonardo Lemos de Souza}

Universidade Estadual Paulista "Júlio de Mesquita Filho" - UNESP

Faculdade de Ciências e Letras de Assis

Programa de Pós-Graduação em Psicologia - Departamento de Psicologia Clínica

Av. Dom Antonio, 2100, Parque Universitário, CEP 19806-900, Assis - SP, Brasil

Endereço eletrônico: leo.lemos.souza@gmail.com

Recebido em: 01/12/2014

Reformulado em: 08/10/2015

Aceito para publicação em: 02/11/2015

\section{Notas}

* Mestre em Psicologia pela Universidade Estadual Paulista "Júlio de Mesquita Filho" (UNESP) - Campus de Assis; Docente de graduação em Psicologia das Faculdades Integradas de Ourinhos (FIO) e Faculdade da Alta Paulista (FAP). Membro do Grupo de Estudos e Pesquisas sobre as Sexualidades - GEPS

** Doutor em saúde coletiva pela Universidade do Estado do Rio de Janeiro; PósDoutorado em Psicologia e Estudos de Gênero pela Universidade de Buenos Aires; Docente de graduação e pós-graduação em Psicologia pela Universidade Estadual Paulista "Júlio de Mesquita Filho" (UNESP) - Campus de Assis. Membro do Grupo de Estudos e Pesquisas sobre as Sexualidades - GEPS

*** Mestre em Psicologia pela Universidade Estadual Paulista “Júlio de Mesquita Filho" (UNESP) - Campus de Assis; Docente de graduação em Psicologia das Faculdades Integradas de Três Lagoas/MS (AEMS) e Faculdade da Fundação Educacional Araçatuba. Membro do Grupo de Estudos e Pesquisas sobre as Sexualidades - GEPS

**** Doutor em Educação pela Universidade Estadual de Campinas; Estágio PósDoutoral no Departamento de Psicologia Básica da Facultat de Psicologia da Universitat de Barcelona; Docente de graduação e pós-graduação em Psicologia pela Universidade Estadual Paulista "Júlio de Mesquita Filho" (UNESP) - Campus de Assis. Membro do Grupo de Estudos e Pesquisas sobre as Sexualidades - GEPS

${ }^{1}$ Dados encontrados em pesquisa, demonstram que entre o triênio de 2009 a 2011 as taxas de feminicídios vieram a aumentar no Brasil, principalmente entre a população negra, jovem e com baixa escolaridade (Garcia, Freitas, Silva \& Höfelmann, 2015; César, Duarte \& Sierra, 2013).

${ }^{2}$ Atualmente a autora passou a utilizar o nome Raewyn Connel.

${ }^{3}$ Vale ressaltar que ao longo deste artigo utilizaremos o termo Queer/Teoria Queer, que é originário da língua inglesa (queer é derivado do alemão "que" e significa desviado, torcido) por não existir na língua portuguesa uma palavra que possa ser utilizada para traduzi-la ou substituí-la - vale destacar que no Brasil os termos viado, boiola, bicha, sapatão, traveco, entre outros que são utilizados para menosprezar formas identitárias que fogem às normas, seriam equivalentes ao termo queer empregado pelxs americanxs em meados dos anos 20 do século passado e utilizado por homossexuais para se auto afirmarem até meados dos anos 30, quando se generaliza o termo "gay"; no entanto, acreditamos que estes termos não teriam a mesma eficácia e não carregariam consigo toda carga política, histórica, cultural, social e teórica que o termo Queer traz (Córdoba, 2005; Penedo, 2008; Salih, 2012).

${ }^{4}$ É interessante assinalar que esta dinâmica do medo nos mostra que "ser um homem" é um lugar vazio. Quer dizer, é impossível escrever ou definir em que consiste ser homem. Nem se quer isso que chamamos masculinidade é algo privativo ou próprio dos homens, como mostrou Judith Halberstan em seu trabalho pioneiro sobre a participação das mulheres na produção da masculinidade (Masculinidade feminina). Vemos nestes processos que "ser um homem" se baseia 
em "não ser" outras coisas: não ser mulher, não ser homossexual. É uma identidade gerada por oposição, por negação, ou pela repetição de alguns gestos estéticos ou de conduta que carecem dos originais, é uma noção sem conteúdo preciso. O poder dos homens, o poder patriarcal e machista, é construído por uma parte, por meio desse desprezo as mulheres e, por outra parte, pelo ódio aos homens considerados menos masculinos, os gays. (p.62) (Tradução livre) 